\title{
Correction to: The optimal cutting times of multipass abrasive water jet cutting
}

\author{
Xiaojin Miao $^{1} \cdot$ Zhengrong Qiang $^{1} \cdot$ Meiping $\mathrm{Wu}^{1} \cdot$ Lei Song $^{1} \cdot$ Feng Ye $^{1}$
}

Published online: 2 January 2020

(C) Springer-Verlag London Ltd., part of Springer Nature 2020

\section{Correction to: The International Journal of Advanced} Manufacturing Technology, Volume 97, Issue 5, pp 1779-1786 https://doi.org/10.1007/s00170-018-2011-0

Author Meiping Wu wmp169@jiangnan.edu.cn should also be declared as the corresponding author of the article https://doi.org/10.1007/s00170-018-2011-0.

Publisher's note Springer Nature remains neutral with regard to jurisdictional claims in published maps and institutional affiliations.

The online version of the original article can be found at https://doi.org/ 10.1007/s00170-018-2011-0

Xiaojin Miao

miaoxiaojin126@126.com

Meiping Wu

wmp169@jiangnan.edu.cn

1 School of Mechanical Engineering, Jiangnan University,

Wuxi 214122, China 